\title{
Comparative Study of Copolymerization and Terpolymerization of Ethylene/Propylene/Diene Monomers Using Metallocene Catalyst
}

\author{
M. Mortazavi, ${ }^{1}$ H. Arabi, ${ }^{1}$ S. Ahmadjo, ${ }^{1}$ M. Nekoomanesh, ${ }^{1}$ G. H. Zohuri ${ }^{2}$ \\ ${ }^{1}$ Department of Catalyst, Iran Polymer and Petrochemical Institute, Tehran, Iran \\ ${ }^{2}$ Department of Chemistry, Faculty of Science, Ferdowsi University of Mashhad, Mashhad, Iran
}

Received 18 January 2010; accepted 29 January 2011

DOI 10.1002/app.34251

Published online 10 June 2011 in Wiley Online Library (wileyonlinelibrary.com).

\begin{abstract}
Ind) ${ }_{2} \mathrm{ZrCl}_{2}$ catalyst was synthesized and used for copolymerization of ethylene and propylene (EPR) and terpolymerization of ethylene propylene and 5-ethyldiene-2-norbornene (ENB). Methylaluminoxane (MAO) was used as cocatalyst. The activity of the catalyst was higher in copolymerization of ethylene and propylene (EPR) rather than in terpolymerization of ethylene, propylene and diene monomers. The effects of [Al] : [Zr] molar ratio, polymerization temperature, pressure ratio of ethylene/propylene and the ENB concentration on the terpolymerization behavior were studied. The highest productivity of the catalyst was obtained at $60^{\circ} \mathrm{C},[\mathrm{Al}]$ : [ $\left.\mathrm{Zr}\right]$ molar ratios of $750: 1$ and 500 : 1 for copolymerization and terpolymerization, respectively. Increasing the molar ratio of $[\mathrm{Al}]:[\mathrm{Zr}]$ up to $500: 1$ increased the ethylene and ENB contents of the terpolymers, while beyond this ratio the productivity of the cata-
\end{abstract}

lyst dropped, leading to lower ethylene and ENB contents. Terpolymerization was carried out batchwise at temperatures from 40 to $70^{\circ} \mathrm{C}$. Rate time profiles of the polymerization were a decay type for both copolymerization and terpolymerization. Glass transition temperatures $\left(T_{g}\right)$ of the obtained terpolymers were between -64 and $-52^{\circ} \mathrm{C}$. Glass transition temperatures of both copolymers and terpolymers were decreased with increased ethylene content of the polymers. Dynamic mechanical and rheological properties of the obtained polymers were studied. A compounded EPDM showed good thermal stability with time. (C) 2011 Wiley Periodicals, Inc. J Appl Polym Sci 122: 1838-1846, 2011

Key words: metallocene catalyst; homogeneous catalyst; copolymerization; EPR; ethylene/propylene/diene terpolymerization; EPDM

\section{INTRODUCTION}

Ethylene/propylene copolymer and its terpolymers with dienes known as EPDM are commercially important materials. In most technical processes for production of EPDM rubbers, soluble or highly dispersed vanadium compounds such as $\mathrm{VCl}_{4}$, $\mathrm{V}(\mathrm{acac})_{3}, \mathrm{VOCl}_{3}, \mathrm{VO}(\mathrm{OR})_{3}$, cocatalyzed by alkylaluminum chloride in presence of an organic halogen promoter or in some cases titanium catalysts, are used. It is inconvenient to use vanadium, because the residual vanadium content in the polymer of above $10 \mathrm{ppm}$ causes discoloration, aging, and toxicity. ${ }^{1-6}$ In addition, these vanadium-based catalysts drastically lose productivity in presence of dienes. Furthermore, the diene concentration in the polymer is limited due to side reactions and crosslinking in the course of terpolymerization. ${ }^{7}$ Recently, single-site catalysts have found more applications in industrial polyolefin production. A well-known distinct feature of the single-site catalysts is in their ability to copolymerize ethylene with $\alpha$-olefins in a homogene-

Correspondence to: H. Arabi (H.Arabi@ippi.ac.ir).

Journal of Applied Polymer Science, Vol. 122, 1838-1846 (2011) (c) 2011 Wiley Periodicals, Inc. ous fashion. The application of single site catalysts has been limited to ethylene/ $\alpha$-olefin copolymers like LLDPE, plastomers, elastomers and EPDM. ${ }^{8-10}$ There is an advantage of metallocene compared to Zigler-Natta catalyst in EPDM production, both by the desire to avoid the use of toxic vanadium and to exploit the well-known high activities of the metallocene systems. These catalysts have the ability to allow random distributions of monomers and to provide good control over molecular weight distribution. ${ }^{11-13}$ The homogeneous metallocene catalysts have been extensively investigated by many researchers. ${ }^{14-16}$ The studies show that metallocene catalyst exhibits higher activities and higher incorporation rates of termonomers in the polymer without any noticeable side reactions. ${ }^{8,17-19}$ The production of EPDM grades can be modulated by proper choice of monomer ratio, reaction temperature, catalyst, cocatalysts and diene concentrations.

In the present work, the catalyst (Ind) ${ }_{2} \mathrm{ZrCl}_{2}$ was synthesized and the effects of polymerization conditions such as polymerization temperature, cocatalyst concentration, feed ratio of ethylene/propylene (E/ $\mathrm{P})$ and diene content were studied in their corresponding copolymerization and the terpolymerization processes. The properties and characterization 
of the final copolymers and terpolymers were also studied.

\section{EXPERIMENTAL}

Indene (purity 90\%) was purchased from Aldrich (Munich-Germany). Zirconium tetrachloride (98\%) and methyllithium (5\% in diethyl ether) were provided by Merck (Munich, Germany) and used as received. All solvents were provided from Luba (India), dried and deoxygenated according to the methods adopted from the literature. ${ }^{20-22}$ Triisobutyl aluminum (TIBA), methylaluminoxane (MAO) $(10 \%$ in toluene) and 5-ethyldiene-2-norbornene (ENB) $(99 \%)$ were purchased from Aldrich (Munich, Germany). ENB was received in a stabilized form and was claimed to be a mixture of nearly equimolar endo and exo forms. This chemical was distilled over calcium hydride under reduced pressure. Polymerization grade gases such as ethylene (E) and propylene (P) (purity 99.9\%) were supplied by Iran Petrochemical (Tehran, Iran) and were purified by passing through columns of activated 13X and $4 \AA$ molecular sieves. Nitrogen gas (purity 99.99\%) was purchased from Roham (Tehran, Iran) and was purified by passing through columns of activated silica gel, $\mathrm{KOH}, \mathrm{P}_{2} \mathrm{O}_{5}$, and $4 \AA$ molecular sieves.

Ethylene and diene wt \% contents of the final polymer were measured according to ASTM D39002002 and ASTM D6047-2002 standards based on FTIR calculation, respectively. IR (FTIR, Bruker model IFS48) and NMR $400 \mathrm{MHz}$ model Avance 400 Bruker techniques were used for structural characterization. For NMR study, the solutions were prepared in 1,3,5-trichlorobenzene and 1,1,2,2 tetrachloroethane-d (20 vol \%) for an internal lock signal, ${ }^{13} \mathrm{C}$-NMR spectra were recorded at $120^{\circ} \mathrm{C}$. A calibration curve for samples of known diene was also obtained to determine similar diene content in the obtained polymers. Characterizations of some selected polymers were performed using this technique, assignment of the peaks and the compositional analyses of the samples were being carried out based on published works. ${ }^{13,18}$ Determination of the glass transition temperature was performed using DSC PL model STA 780 in temperature range of $25-150^{\circ} \mathrm{C}$. Dynamic mechanical thermal analysis (DMTA) was performed using DMTA PL model. The temperature scanning was performed in the range of $-100-50^{\circ} \mathrm{C}$ at a heating rate of $5^{\circ} \mathrm{C} / \mathrm{min}$ and frequency of $1 \mathrm{~Hz}$. Mooney viscosity was measured with Zwick 4309 apparatus. Polymix 200 L ODR rheometer was used to determine curing characteristics data for compounds at $180^{\circ} \mathrm{C}$ in accordance with the test procedures set in ASTM D 2084. The samples were vulcanized at $180^{\circ} \mathrm{C}$ in a 25 ton hydraulic press (Davenport, England) under $180 \mathrm{~kg} /$ $\mathrm{cm}^{2}$ pressure for a period based on data obtained from the rheometer. The rheological characterization of EPDM sample was carried out using an Anton paar MCR 300 stress controlled rheometer. The experiments were performed in parallel-plate geometry with a diameter of $25 \mathrm{~mm}$ under a nitrogen atmosphere at a temperature $180^{\circ} \mathrm{C}$ using $0.01-80 \mathrm{~Hz}$ frequency range.

Polymerizations were carried out in a 1-L stainless steel reactor of Buchi (Buchiglauster bmd 300) with double feed and semibatch type reactor and fully controlled system of temperature, stirring speed, and reaction pressure.

Volumetric flow rate and the ratio of monomers supplied to the reactor were controlled by a mass flowmeter. The reactor was purged with $\mathrm{N}_{2}$. Toluene $(400 \mathrm{~mL})$ was charged into the reactor and degassed at least three times. The reactor was heated to the required temperature. The catalyst components were added in the following order: TIBA, MAO, ENB, and solution of the catalyst toluene. The pressure inside the reactor remained constant at 1 bar. Therefore, the required amounts of the monomer mixtures fed into were approximately equal to the consumed monomers, which were controlled by a pressure sensor and a mass flowmeter. At the end of the polymerization (usually $1 \mathrm{~h}$ ) the content of the reactor was poured into an excess of acidified methanol, stirred for few hours, filtered and dried at $70^{\circ} \mathrm{C}$.

\section{Catalyst preparation}

The catalyst (Ind) ${ }_{2} \mathrm{ZrCl}_{2}$ was synthesized using a method based on literature. ${ }^{23}$ Methyllithium $(5 \%$ in diethyl ether, $20 \mathrm{mmol}$ ), was added to a solution of indene $\left(2.4 \mathrm{~g}\right.$ in $\left.30 \mathrm{~mL} \mathrm{Et}_{2} \mathrm{O}\right)$ dropwise. The mixture was stirred for $40 \mathrm{~min}$ at room temperature. The resulting solution was added to $\mathrm{ZrCl}_{4}(10 \mathrm{mmol}$ in $30 \mathrm{~mL}$ pentane) at once. The suspension was stirred for further $2 \mathrm{~h}$ at room temperature. The final product was filtered and the residue was refluxed for $6 \mathrm{~h}$ in $\mathrm{CH}_{2} \mathrm{Cl}_{2}(100 \mathrm{~mL})$. The filtrate was dried to obtain (Ind) ${ }_{2} \mathrm{ZrCl}_{2}$. The yield was $60 \%$.

\section{RESULTS AND DISCUSSION}

\section{Copolymerization of ethylene and propylene}

Copolymerization of ethylene and propylene was carried out using the metallocene catalyst, while TIBA and MAO were used as a scavenger and cocatalyst, respectively. Our experiments indicated that the presence of TIBA is not so influential on polymerization behavior therefore we did not use TIBA in the subsequent experiments. Furthermore [Al] values only refer to MAO concentration (except Table I and Fig. 2 that refer to TIBA and MAO 
TABLE I

Copolymerization in Different Feed Ratio

\begin{tabular}{ccccc}
\hline $\begin{array}{c}\text { Activity } \\
(\mathrm{kg} \mathrm{P} / \mathrm{mol} \mathrm{zr} \mathrm{h})\end{array}$ & $\begin{array}{c}\text { Ethylene } \\
(\text { wt \%) }\end{array}$ & $\begin{array}{c}\mathrm{T}_{g} \\
\left({ }^{\circ} \mathrm{C}\right)\end{array}$ & $\begin{array}{c}\text { Polymer } \\
(\mathrm{g})\end{array}$ & $\begin{array}{c}\text { Feed ratio } \\
(\mathrm{E} / \mathrm{P})(\mathrm{mL} / \mathrm{mL})\end{array}$ \\
\hline 2580 & 82 & -83 & 25.8 & $80: 20$ \\
2260 & 75 & -66 & 22.6 & $67: 33$ \\
1200 & 72 & -77 & 12.0 & $50: 50$ \\
760 & 62 & -60 & 7.6 & $33: 67$ \\
\hline
\end{tabular}

Polymerization conditions: Temperature $=60^{\circ} \mathrm{C},[\mathrm{Zr}]=$ $10^{-5} \mathrm{~mol}, \mathrm{MAO}=5 \mathrm{mmol}$, TIBA $=2.5 \mathrm{mmol}, P_{\text {internal }}=1$ bar, and $[\mathrm{Al}]:[\mathrm{Zr}]=750$.

concentrations together). Ethylene and propylene (E/P) feed ratios of $80 / 20,67 / 33,50 / 50$, and $33 / 67$ $\mathrm{mL} / \mathrm{mL}$, were used in copolymerization process. The activity of the catalyst is reduced with decreased $\mathrm{E} / \mathrm{P}$ feed ratio, which is a common behavior in a similar polymerization process ${ }^{2,16}$ (Table I). The rates of the reaction based on monomer consumptions are presented in Figure 1. The polymerization reaction shows a decay type with short induction period while the consumption rate is increased to its maximum point after $5-8 \mathrm{~min}$, followed by a slower rate due to catalyst deactivation. Similar observations have been reported. ${ }^{24,25}$ The decay behavior may be attributed to lowering activity of some active centers with time. Copolymerizations were carried out using a homogeneous catalyst system which is generally characterized by decay processes after the first few minutes of reaction especially when longer olefins are employed as comonomers. ${ }^{26}$

Figure 2 shows the effect of $[\mathrm{Al}]:[\mathrm{Zr}]$ molar ratio on the average rate of copolymerization. The molar ratios to about $[\mathrm{Al}]:[\mathrm{Zr}]=750: 1$ increase the activity of the catalyst, and beyond this ratio it is slightly decreased. Higher concentrations of MAO probably shift the reaction equilibrium towards generation of inactive species. This behavior is possibly due to ex-

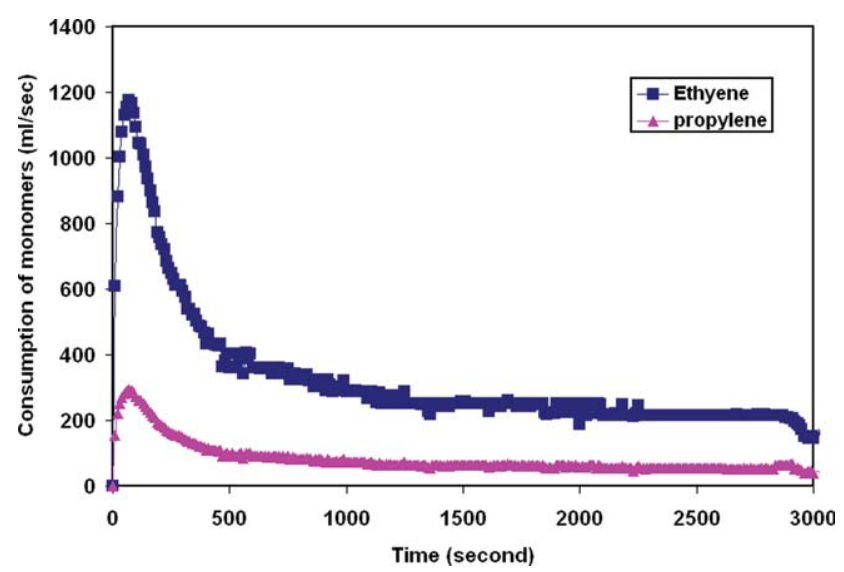

Figure 1 Effect of reaction time on monomer consumption. Polymerization condition $\mathrm{E} / \mathrm{P}=80 / 20$, other condition is as in Table I. [Color figure can be viewed in the online issue, which is available at wileyonlinelibrary.com.]

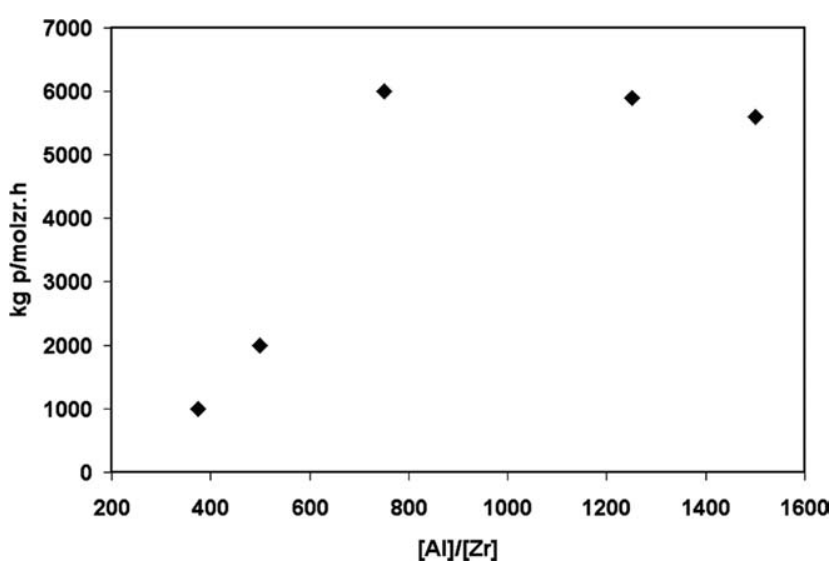

Figure 2 Effect of [Al] : [Zr] molar ratio on average rate of copolymerization, under the condition given in Table I.

cessive complexation of MAO with the active centers. Therefore, the vacant coordination positions at these active centers become unavailable for the monomer complexation. ${ }^{5,27}$

\section{Terpolymerization of ethylene, propylene and diene monomers}

Terpolymerization of ethylene, propylene and 5-ethylidiene-2-norbornene was carried out using the synthesized metallocene catalyst in different feed ratios (Table II). The effects of [Al] : [Zr] molar ratio and polymerization temperature on the polymerization behavior were studied at constant feed ratio $(\mathrm{E} / \mathrm{P}=$ 80/20) as given in Table III. The polymerization activity was increased to the optimum value of $312(\mathrm{~kg}$ polymer $\mathrm{mol}^{-1} \mathrm{Zr} \mathrm{h}^{-1}$ ) with [Al] : [Zr] molar ratio reaching $500: 1$, where beyond this ratio the

TABLE II

Terpolymerization Using (Ind) ${ }_{2} \mathrm{ZrCl}_{2}$ /MAO Catalyst System in Different Feed Ratio

\begin{tabular}{|c|c|c|c|c|c|c|}
\hline $\begin{array}{l}E / P \\
\text { feed } \\
\text { ratio }\end{array}$ & $\begin{array}{l}\text { ENB in } \\
\text { reactor } \\
(\mathrm{mol} / \mathrm{L})\end{array}$ & $\begin{array}{l}\mathrm{ENB}^{\mathrm{a}} \\
(\mathrm{wt} \%)\end{array}$ & $\begin{array}{l}\text { Ethylene }^{a} \\
\text { (wt \%) }\end{array}$ & $\begin{array}{c}\text { Polymer } \\
\text { (g) }\end{array}$ & $\begin{array}{c}\text { Activity } \\
\text { kg P/ } \\
\text { mol Zr h }\end{array}$ & $\begin{array}{c}T_{g} \\
\left({ }^{\circ} \mathrm{C}\right)\end{array}$ \\
\hline $80: 20$ & 0.05 & 1 & 83 & 18.64 & 1864 & -60 \\
\hline $80: 20$ & 0.1 & 4 & 85 & 9.7 & 970 & -53 \\
\hline $80: 20$ & 0.14 & 5 & 77 & 2.2 & 220 & -54 \\
\hline $80: 20$ & 0.19 & 10 & 74 & 3.2 & 320 & - \\
\hline $67: 33$ & 0.05 & 2 & 72 & 8.67 & 867 & -52 \\
\hline $67: 33$ & 0.1 & 6 & 70 & 2.6 & 260 & - \\
\hline $50: 50$ & 0.05 & 3 & 68 & 2.3 & 230 & - \\
\hline $50: 50$ & 0.1 & 7 & 66 & 2.3 & 230 & - \\
\hline $67: 33^{b}$ & 0.14 & 1.4 & 87 & 34 & 1700 & -64 \\
\hline $50: 50^{b}$ & 0.14 & 2 & 80 & 26 & 1300 & -60 \\
\hline $33: 67^{b}$ & 0.14 & 5.5 & 75 & 20 & 1000 & -57 \\
\hline
\end{tabular}

Temperature $=60^{\circ} \mathrm{C},[\mathrm{Zr}]=10^{-5}(\mathrm{~mol}), \mathrm{MAO}=5$ $\mathrm{mmol}, P_{\text {internal }}=1$ bar.

${ }^{\text {a }}$ Ethylene and ENB contents obtained from FTIR calculation.

${ }^{\mathrm{b}} P_{\text {internal }}=4 \mathrm{bar}, \mathrm{MAO}=7.5 \mathrm{mmol},[\mathrm{Zr}]=2 \times 10^{-5}$ (mol). 
TABLE III

Terpolymerization Using (Ind) ${ }_{2} \mathrm{ZrCl}_{2} / \mathrm{MAO}$ Catalyst in Feed Ratio 80/20

\begin{tabular}{cccccc}
\hline $\begin{array}{c}\text { [Al] } /[\mathrm{Zr}] \\
\text { molar } \\
\text { ratio }\end{array}$ & $\begin{array}{c}\mathrm{ENB}^{\mathrm{a}} \\
(\text { wt } \%)\end{array}$ & $\begin{array}{c}\text { Ethylene }^{\mathrm{b}} \\
(\text { wt } \%)\end{array}$ & $\begin{array}{c}\text { Polymerization } \\
\text { temperature } \\
\left({ }^{\circ} \mathrm{C}\right)\end{array}$ & $\begin{array}{c}\text { Polymer } \\
(\mathrm{g})\end{array}$ & $\begin{array}{c}\text { Activity } \\
\mathrm{kg} \mathrm{P} / \mathrm{mol} \\
\mathrm{Zr} \mathrm{h}\end{array}$ \\
\hline $250: 1$ & 3.2 & 82 & 60 & 1.5 & 75 \\
$313: 1$ & 3.2 & 78 & 60 & 5.2 & 260 \\
$375: 1$ & 3.4 & 85 & 60 & 5.5 & 275 \\
$500: 1$ & 6.9 & 89 & 60 & 6.4 & 320 \\
$625: 1$ & 4.6 & 75 & 60 & 3.1 & 155 \\
$500: 1$ & 3.5 & 87 & 40 & 4.1 & 205 \\
$500: 1$ & 5.4 & 86 & 50 & 5.4 & 250 \\
$500: 1$ & 5.6 & 88 & 70 & 5 & 270 \\
\hline
\end{tabular}

${ }^{\mathrm{a}} \mathrm{ENB}=0.2 \mathrm{~mol} / \mathrm{L},[\mathrm{Zr}]=2 \times 10^{-5}(\mathrm{~mol}), P_{\text {internal }}=1 \mathrm{bar},(\mathrm{E} / \mathrm{P})$ feed ratio $=80 / 20$.

${ }^{\mathrm{b}}$ Ethylene and ENB contents obtained from FTIR calculation.

productivity of catalyst is diminished (Fig. 3). The diene monomer decreases the activity of the catalyst in comparison with copolymerization. As a result the optimum molar ratio of $[\mathrm{Al}]:[\mathrm{Zr}]$ shifts to lower value for terpolymerization relative to copolymerization in relation to their activity of the catalyst.

The highest activity of catalyst is reached at $60^{\circ} \mathrm{C}$ (Fig. 4), where beyond this value the activity is decreased, as reported by other researchers. ${ }^{28}$ At high temperatures, monomer concentration drops and propagation rate is also lowered with deactivation of active sites due to structural changes or due to higher deactivation rates used at experimental conditions. ${ }^{29}$

\section{Polymer characterization}

It is observed that the diene content of the obtained polymer is dependent on E/P monomer feed ratio, where by increasing the ENB concentration the ethylene content and the productivity of the catalyst system are reduced (Tables II and III). However, diene content may be increased with lower ethylene

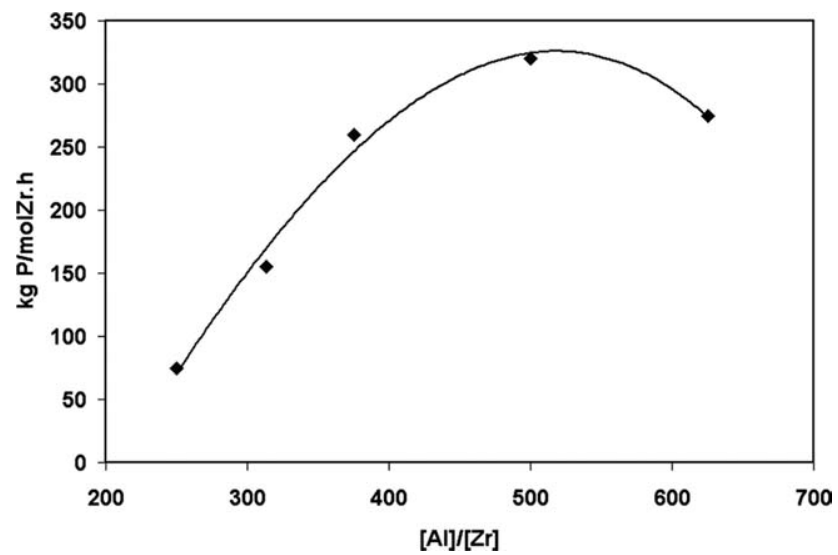

Figure 3 Effect of [Al] : [Zr] on average rate of polymerization, under the condition given in Table III. content of E/P monomer feed ratios, in accordance with other reports. ${ }^{13,16}$ Both ethylene and ENB contents of the polymers are increased with $[\mathrm{Al}]:[\mathrm{Zr}]$ molar ratio up to $500: 1$, however beyond this ratio their contents are decreased in final terpolymer composition (Figs. 5 and 6). This behavior is a clear indication that at higher ratios of $[\mathrm{Al}]:[\mathrm{Zr}]$ the catalyst system tends to allow the polymerization of propylene rather than ethylene. ${ }^{5}$ Increasing the temperature of polymerization leads to decreases in ethylene content and at temperature beyond $60^{\circ} \mathrm{C}$ the ENB content of the obtained polymer is dropped (Figs. 7 and 8). This behavior is attributed to lowering monomer concentration by temperature increases. ${ }^{2,28}$ In some cases we do not obtain the desired EPDM due to polymer with more than $80 \%$ ethylene originating from high ethylene content of monomer feed ratio $(\mathrm{E} / \mathrm{P}=80 / 20)$. However, $\mathrm{EPDM}$ was obtained under different conditions under smaller $E / P$ feed ratio and higher internal pressure (Table II). ENB contents of the polymers are also increased with increased amount of ENB in the feed ratios (Fig. 9).

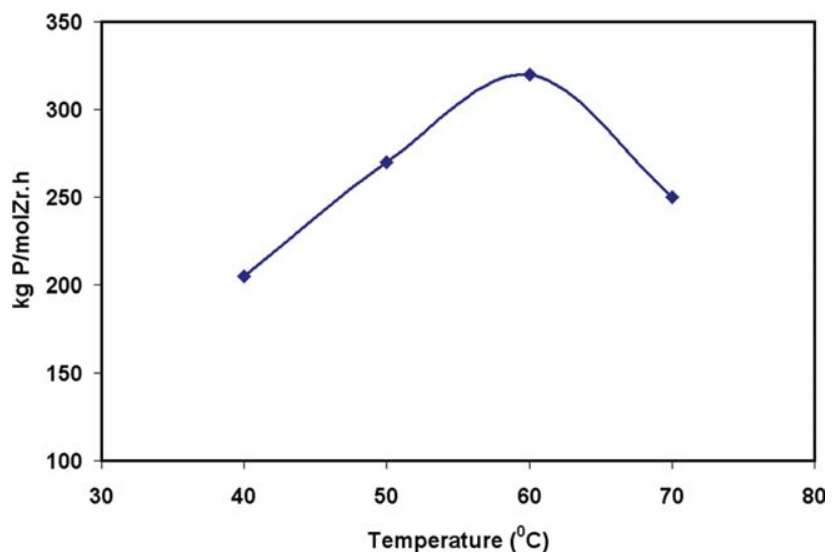

Figure 4 Effect of temperature on average rate of polymerization, under the condition given in Table III. [Color figure can be viewed in the online issue, which is available at wileyonlinelibrary.com.] 


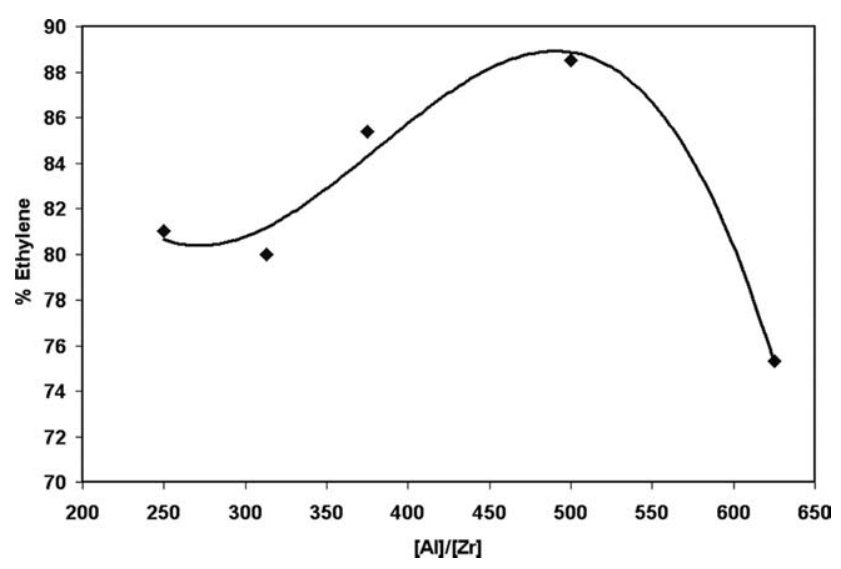

Figure 5 Effect of [Al] : [Zr] molar ratio on ethylene content of polymer, obtained under the conditions given in Table III.

As it is known, ${ }^{13} \mathrm{C}-\mathrm{NMR}$ is one of the most powerful techniques used to characterize the microstructure of a polymer. The triad distributions of ethylene, propylene of some EPDMs and the spectra of ${ }^{13} \mathrm{CNMR}$ samples are presented in Table IV and Figure 10, respectively. To study the crystallization behavior of the samples we also used DSC within temperature range of $30-130^{\circ} \mathrm{C}$ (Table IV).

It may be observed that $T_{m}$ increases with increasing the ethylene content due to the crystallinity of EEE block segments in PE. However, with $\mathrm{E} / \mathrm{P}<1$ feed ratio the $T_{m}$ and crystallinity are decreased. The similar PPP triad distribution near zero quantity was observed for some samples, However, it is revealed that the EEE block segment is predominant even at $\mathrm{E}<\mathrm{P}$ monomer feed ratio. Increasing the ethylene content in the polymer increases the EEE triad distribution and decreases PPP block segments. The content of alternating triad distributions of EPE and PEP are very low. The last sample shows the lowest EEE triad distribution that is supposed to be due to

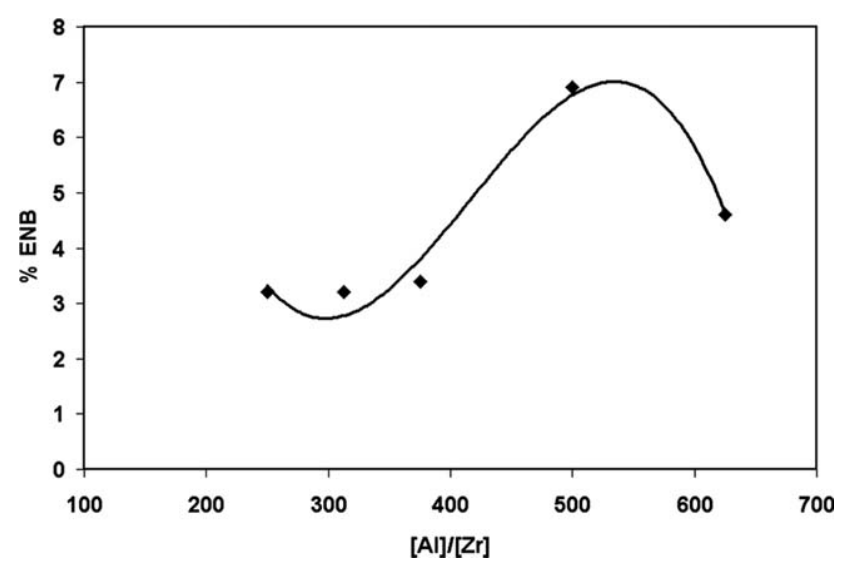

Figure 6 Effect of $[\mathrm{Al}]$ : [Zr] molar ratio on diene (ENB) content of polymer, obtained under the condition given in Table III.

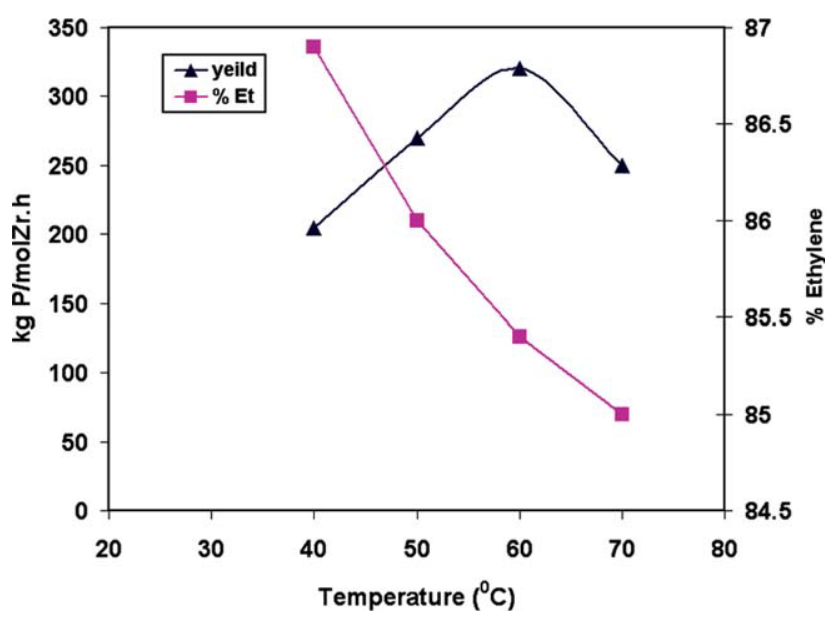

Figure 7 Effects of temperature on ethylene content and productivity of polymers, obtained under the conditions given in Table III. [Color figure can be viewed in the online issue, which is available at wileyonlinelibrary.com.]

suitable incorporation of propylene and diene monomers. It can be observed that triad distributions have fewer tendencies to build the PP block segments, which is characteristic of zirconocene catalyst in homogeneous system. ${ }^{30}$ As it is observed the thermal properties such as $T_{m}$ and percentage crystallinity are also dependent on the fraction of propylene and ENB in the polymer backbone. When propylene and ENB contents are increased the melting point and percentage crystallinity of the final polymers are decreased.

The properties of some terpolymers with high ethylene content were studied with DMTA, at temperature range between -100 and $50^{\circ} \mathrm{C}$. Commercial EPDMs have glass transition temperatures between -55 and $-60^{\circ} \mathrm{C}$, although samples with higher diene or lower ethylene content may show $10-20^{\circ} \mathrm{C}$ higher $T_{g}{ }^{31}$ Study of the glass transition temperature of the copolymer samples reveal that as soon as the

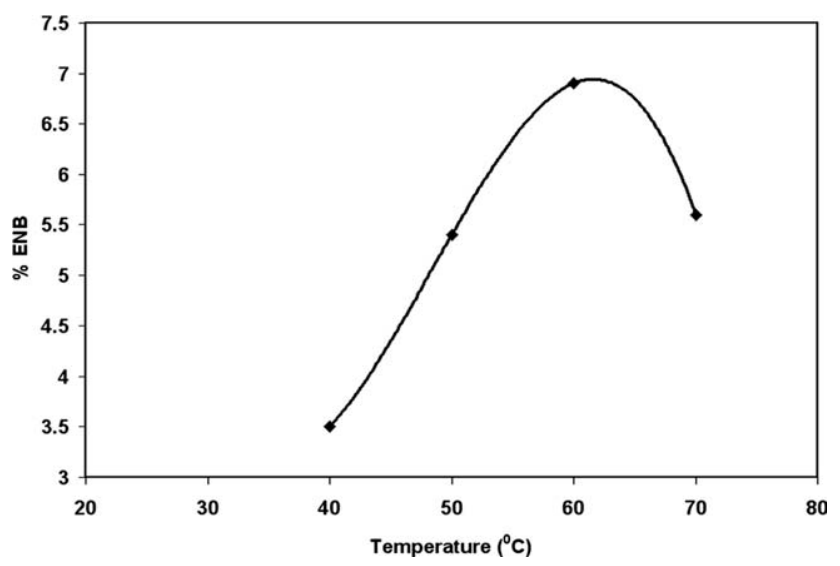

Figure 8 Effect of terpolymerization temperature on diene (ENB) content of polymer, obtained under the condition given in Table III. 


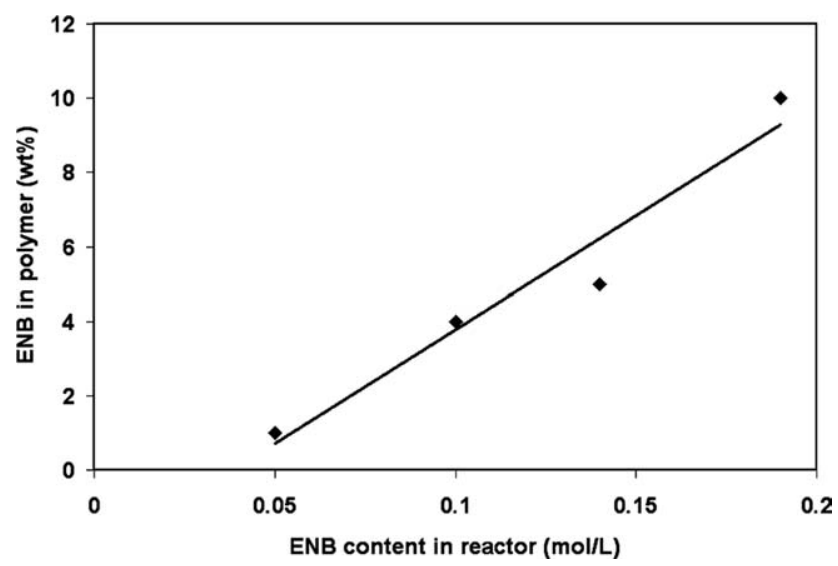

Figure 9 ENB concentration in the reactor versus ENB content of the polymer at $\mathrm{E} / \mathrm{P}=80: 20$ monomer feed ratio.

ethylene content of the polymer is increased its $T_{g}$ is dropped, for instance the sample $\mathrm{C} 1$ (with $82 \%$ ethylene) shows the lowest $T_{g}=-89^{\circ} \mathrm{C}$, while the sample C2 (with $62 \%$ ethylene) shows $T_{g}=-60^{\circ} \mathrm{C}$. A similar behavior is observed for the terpolymer samples. Glass transition temperature of the terpolymer samples are between -52 and $-64^{\circ} \mathrm{C}$. The T4 (with $80 \%$ ethylene and $2 \%$ ENB) shows the $T_{g}=-60^{\circ} \mathrm{C}$, however, the T2 (with $72 \%$ ethylene and 2\% ENB) has the $T_{g}=-52^{\circ} \mathrm{C}$. As it is shown in Figure 11, C1 has the highest storage modulus. The behavior could be due to the highest ethylene content of sample. The storage modulus has a direct relationship to material stiffness. ${ }^{32}$ Above the glass transition temperature, storage modulus changes with crystallinity, and the samples with high ethylene content and high crystallinity such as C1, T1, T3, T4 show higher stiffness. Below the glass transition temperature of EPR samples, the $\mathrm{C} 1$ (with $82 \%$ ethylene) has the highest and surprisingly the C3 (with $72 \%$ ethylene) has the lowest storage modulus, where in terpolymers, T1 (with $85 \%$ ethylene and $4 \%$ ENB) has the highest and T2 (with 70\% ethylene and 6\% ENB) has the lowest storage modulus.

Damping factor $(\tan \delta)$ of the samples is shown in Figure 12. Differences in comonomer content and monomer distribution in final copolymers are reflected in the location and intensity of $\tan \delta .^{33,34}$ High intensity of the $\tan \delta$ curve may also indicate higher impact strength of the material at temperatures below zero. ${ }^{35}$ All EPR samples show high tan $\delta$, except $\mathrm{C} 1$ because of its high ethylene content. In addition, the terpolymer samples display lower glass transition temperature compared to EPR samples due to their higher ethylene contents.

\section{Rheological properties}

Melt rheology provides insight into the relationships between viscoelasticity, molecular structure, and processing performance. Flexible polymers have lower viscosities than rigid polymers of a similar molar mass, and furthermore, any factor that increases the $T_{g}$ tends to increase the viscosity. ${ }^{36}$ Figures 13 and 14 present terpolymers' corresponding elastic modulus and melt complex viscosity curves from dynamic rheological measurements. Commercial sample (KEP 270) shows high elastic modulus at low angular frequency close to $22,000 \mathrm{~Pa}$ and the terpolymers B0, B1, and B2 show their respective elastic modulus of 5400, 200, $400 \mathrm{~Pa}$. These differences can be due to the high ethylene content of the samples of high crystallinity ${ }^{13}$ (Fig. 13). The complex viscosity of commercial EPDM is also higher than that of synthesized samples as shown in Figure 14. However one sample (B0) shows similar behavior in high angular frequency in comparison with KEP 270 due to its nearly equal content of ethylene and ENB. In two other samples (B1 and B2) due to the high ethylene content and different processing conditions, we see high differences in elastic modulus and complex viscosity compared to KEP 270 in all angular frequencies.

\section{Compounding}

The sample with 75\% ethylene and 5.5\% ENB showed moony viscosity of ML $(1+4)$ at $125^{\circ} \mathrm{C}=$ 57. A comparative compounding study of this sample and the commercial EPDM sample KEP 270 in. (Ethylene 57\%, ENB 4.5\%) was conducted using the following formula (ASTM 3568-98):

TABLE IV

Triad Distributions and Crystallinity Properties of Some Obtained Polymers

\begin{tabular}{|c|c|c|c|c|c|c|c|c|c|c|}
\hline Ethylene (\%) & PPP & $\mathrm{EPP}+\mathrm{PPE}$ & $\mathrm{EPE}$ & PEP & $\mathrm{PEE}+\mathrm{EEP}$ & EEE & Crystallinity (\%) & $T_{m}\left({ }^{\circ} \mathrm{C}\right)$ & $\mathrm{E} / \mathrm{P}$ feed ratio & No. \\
\hline 96.2 & 0.0243 & 0.0159 & 0 & 0 & 0.0159 & 0.9457 & 43 & 116 & $80: 20$ & 1 \\
\hline 90.3 & 0.0413 & 0.0336 & 0.0217 & 0.0306 & 0.0159 & 0.8561 & 34 & 112 & $80: 20$ & 2 \\
\hline 88.9 & 0.0302 & 0.0004 & 0.0798 & 0.0038 & 0.1524 & 0.7332 & 39 & 111 & $67: 33$ & 3 \\
\hline 86.9 & 0.0590 & 0.0175 & 0.0549 & 0.0269 & 0.0734 & 0.7682 & 44 & 116 & $50: 50$ & 4 \\
\hline 78.8 & 0.1487 & 0.0097 & 0.0533 & 0.0533 & 0.0097 & 0.7251 & 29 & 88 & $33: 67$ & 5 \\
\hline
\end{tabular}

Ethylene contents obtained from CNMR calculation. 


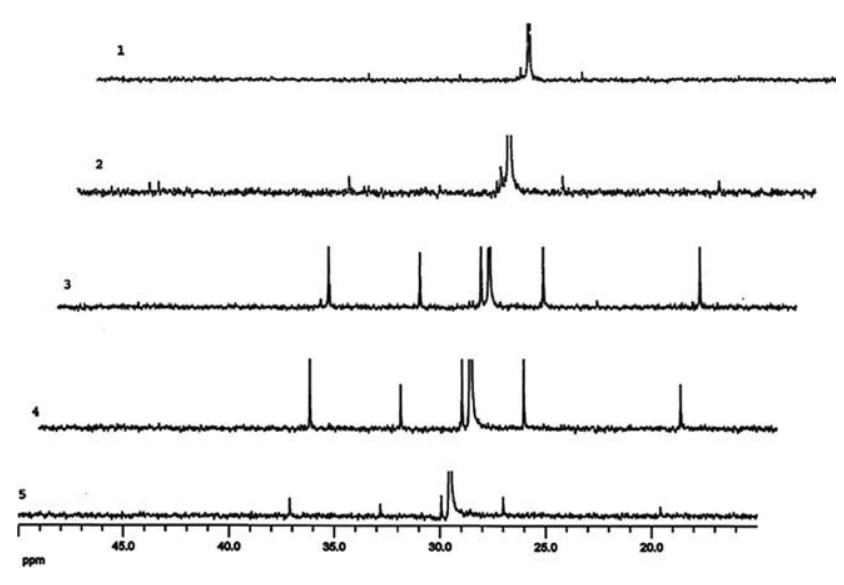

Figure 10 Typical ${ }^{13} \mathrm{C}-\mathrm{NMR}$ spectra of sample obtained under the conditions given in Table IV.

- EPDM: $100 \mathrm{phr}$

- Zinc oxide: 5 phr

- Sulfur: $1.5 \mathrm{ph}$

- Stearic acid: 1 phr

- Carbon black N330: 30 phr

- Naphthenic Behran Oil: 50 phr

- TMTD: 1 phr

- MBT: $0.5 \mathrm{phr}$

Figures 15 and 16 show the rheometer data obtained for the synthesized EPDM and KEP 270 samples, respectively. It can be observed that after about $14 \mathrm{~min}$, a total of $90 \%$ of the curing stage is completed, while for the commercial KEP 270 EPDM the required time was $10.2 \mathrm{~min}$, and after $30 \mathrm{~min}$ at $170^{\circ} \mathrm{C}$ no sign of degradation has been observed in the synthesized EPDM compound, which is an indi-

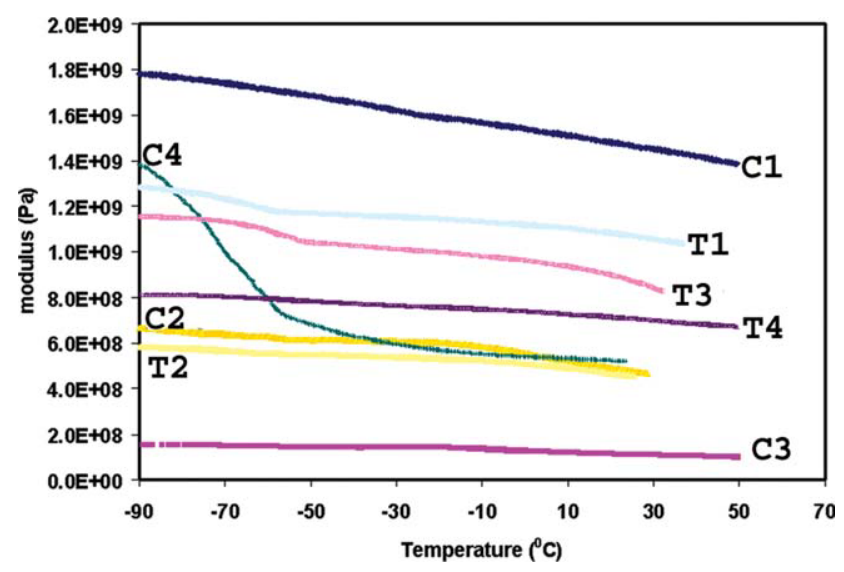

Figure 11 Storage modulus as a function of temperature. C1(82\% ethylene), C2 (75\% ethylene), C3(72\% ethylene), C4(62\% ethylene), T1(85\% ethylene, $4 \%$ ENB), T2 (70\% ethylene, $6 \% \mathrm{ENB})$, T3 (85\% ethylene, 3.4\% ENB), and T4 $(80 \%$ ethylene, 2\% ENB). [Color figure can be viewed in the online issue, which is available at wileyonlinelibrary.com.]

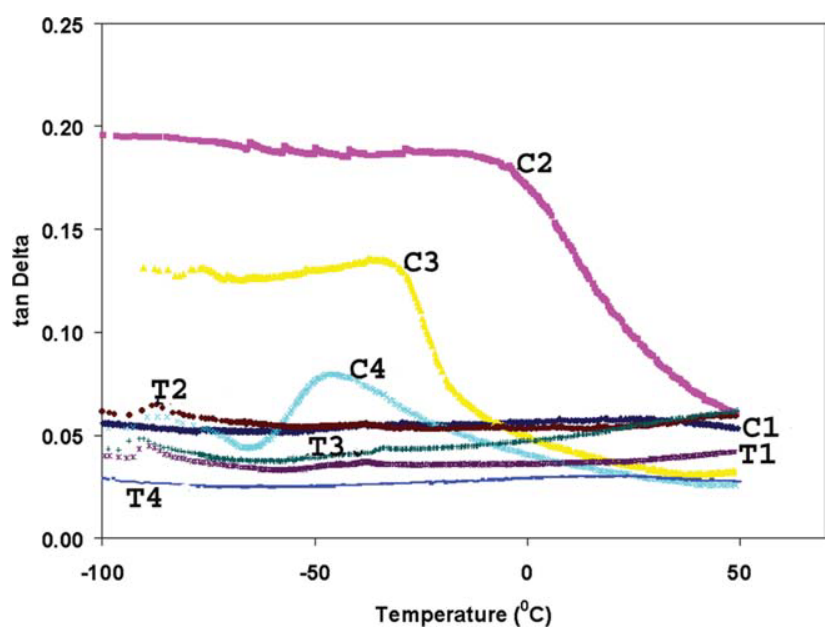

Figure 12 Tan $\delta$ as function of temperature, for samples shown in Figure 11. [Color figure can be viewed in the online issue, which is available at wileyonlinelibrary.com.]

cation of its thermal stability. Similar curing curve was observed for both synthesized EPDM and KEP 270.

\section{CONCLUSION}

(Ind) ${ }_{2} \mathrm{ZrCl}_{2}$ metallocene catalyst was used for copolymerization of ethylene and propylene and in their terpolymerization with diene. In particular, polymerization behaviors were dependent on [Al] : [Zr] molar ratios, temperatures, diene concentrations and monomer feed ratios of E/P. It was revealed that the activity of the catalyst is decreased with the diene addition. There was found an optimum [Al] : [Zr] ratio and a polymerization temperature for obtaining the highest yield of terpolymer. Ethylene

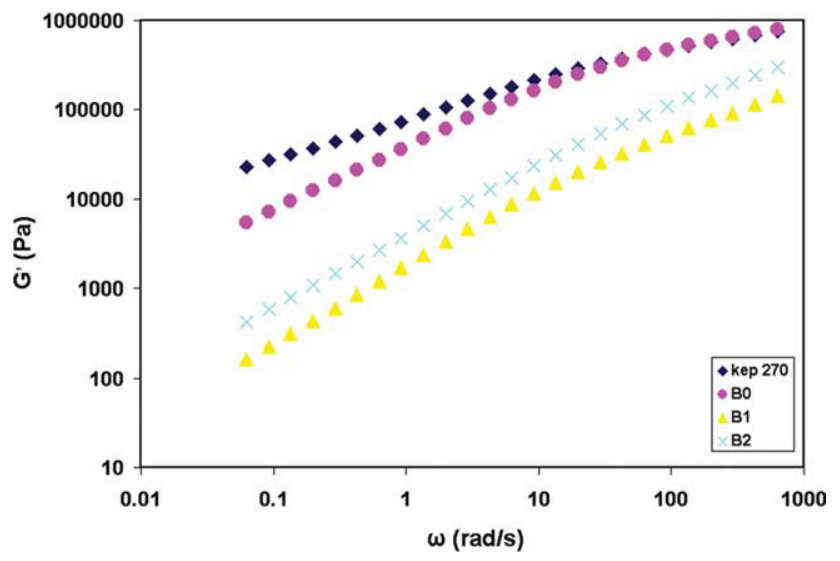

Figure 13 Elastic modulus of commercial and selected terpolymers as a function of angular frequency, polymers specifications: KEP $270=57 \%$ ethylene, $4.5 \%$ ENB; B0 = $70 \%$ ethylene, $5 \%$ ENB; B1 $=77 \%$ ethylene, $5 \%$ ENB; B2 = $72 \%$ ethylene, $2 \%$ ENB. [Color figure can be viewed in the online issue, which is available at wileyonlinelibrary.com.] 


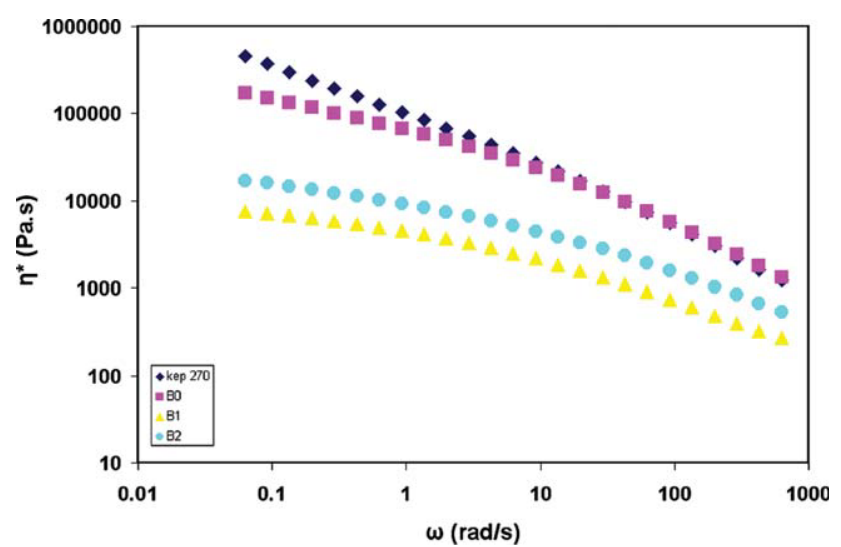

Figure 14 Dynamic viscosity of commercial and selected terpolymers as a function of angular frequency, polymer specification as Figure 13. [Color figure can be viewed in the online issue, which is available at wileyonlinelibrary. com.]

and ENB contents of the terpolymers were between 89 and $70 \%$ and between 1 and $10 \%$ of the given order. Increasing the $[\mathrm{Al}]:[\mathrm{Zr}]$ molar ratio increased the ethylene and ENB contents in the terpolymer. While increasing the polymerization temperature to $60^{\circ} \mathrm{C}$ the ethylene content of the final products was reduced and below this temperature the ENB content increased where it decreased thereafter. Addition of ENB concentration in the feed reduced the ethylene content and productivity of the catalyst. $T_{g}$ of the final terpolymers are between -64 and $-52^{\circ} \mathrm{C}$. Notably with increase in ethylene content there is a decrease in the $T_{g}$ of the resulting polymer. The highest storage modulus is obtained for EPR sample having the highest ethylene content, while terpolymer samples show lower storage modulus relative to EPR samples. The NMR study of some terpolymers shows that triad distributions have lower tendency to build block PP segments rather than block

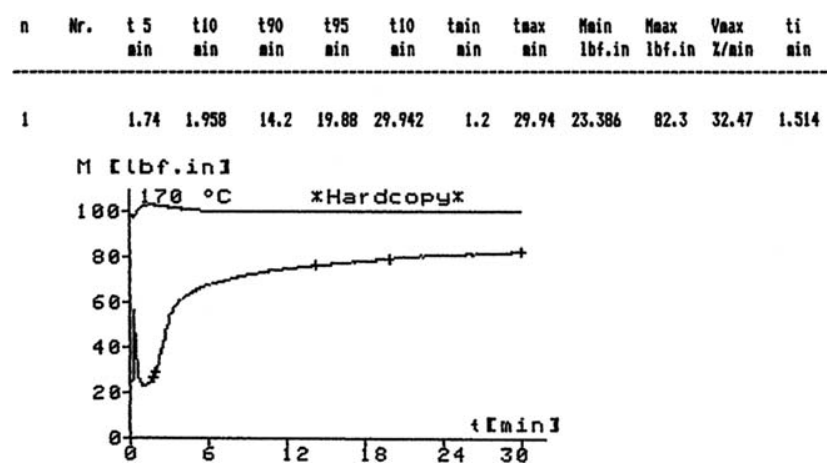

Figure 15 Rheometer of the EPDM compound. Polymerization condition: $\mathrm{ENB}=0.2 \mathrm{~mol} / \mathrm{L},[\mathrm{Zr}],=2 \times 10^{-5}$ $(\mathrm{mol}), \mathrm{MAO}=5 \mathrm{mmol}, P_{\text {internal }}=4 \mathrm{bar},(\mathrm{E} / \mathrm{P})$ feed ratio $=$ $50 / 50$.

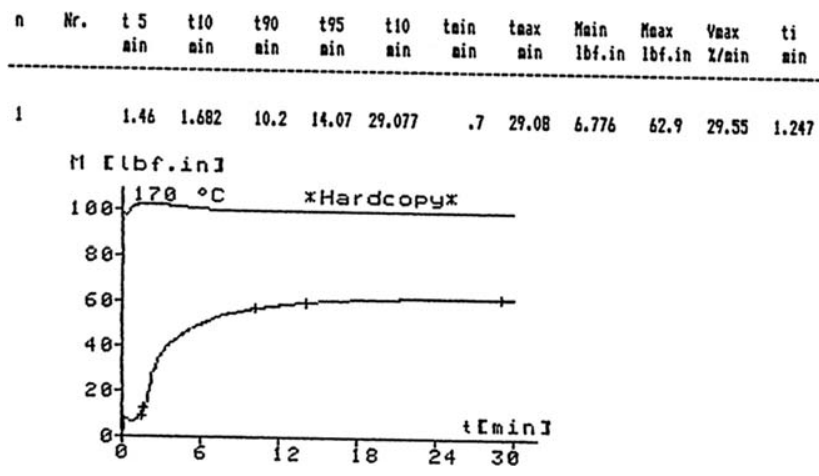

Figure 16 Rheometer of the KEP 270 with $57 \%$ ethylene and $4.5 \%$ ENB compound.

PE segments. Good thermal stability of compounded terpolymer has been confirmed by rheometry.

\section{References}

1. Vasnetsov, S. A. Union Carbide Chemicals and Plastics, Eur Pat. 0712871, June 22, 1996.

2. Zohuri, G. H.; Vakili, M.; Jamjah, R.; Ahmadjo, S.; Nekomanesh, M. Rub Chem Tech 2005, 78, 682.

3. Zohuri, G. H.; Vakeli, M.; Jamjah, R.; Ahmadjo, S.; Nekoomanesh, M. Iran J Polym Sci Tech (Persian) 2004, 16, 327.

4. Zohuri, G. H.; Sadegvandi, F.; Jamjah, R.; Ahmadjo, S.; Nekoomanesh, M.; Bigdelli, E. J Appl Polym Sci 2002, 84, 785.

5. Zohuri, G. H.; Mortazavi, M. M.; Jamjah, R.; Ahmadjo, S. J Appl Polym Sci 2004, 93, 2597.

6. Dong, Q.; Fan, Z. Q.; Fu, Z. S.; Xu, J. T. J Appl Polym Sci 2008, 107, 1301.

7. Haag, M. C.; Dos Santos, J. H. Z.; Stedile, F. C.; Dupont, J. J Appl Polym Sci 1997 1999, 74.

8. Kaminsky, W.; Miri, M. J Polym Sci Polym Chem Ed 1985, 23, 2151.

9. Arrowsmith, D.; Kaminsky, W.; Schauwienold, A. M.; Weingarten, U. J Mol Catal A Chem 2000, 160, 97.

10. Friederichs, N.; Wang, B.; Budzelaar, P. H. M.; Coussens, B. B. J Mol Catal A Chem 2005, 242, 91.

11. Galland, G. B. Dos Santos, J. H. Z.; DallAgnol, M.; Bisatto, R. Macromol Symp 2006, 42, 245.

12. Tritto, I.; Boggioni, L.; Ferro, D. R. Coord Chem Rev 2006, 250, 212.

13. Phoowakeereewiwat, S.; Jongsomjit, B.; Praserthdam, P. J mater Process Tech 2009, 209, 520.

14. Dolatkhuni, M.; Cramail, H.; DefSieux, A. Macromol Chem Phys 1996, 197, 2481.

15. Kaminsky, W.; Laban, A. Appl Catal A Gen 2001, 222, 47.

16. Malmberg. A.; Lofgren, B. J Appl Polym Sci 1997, 66, 35.

17. Dolatkhuni, M.; Cramail, H.; DefSieux, A. Macrornol Chem Phys 1996, 191, 289.

18. Bavarian, N.; Baird, M. C.; Parent, J. S. Macromol Chem Phys 2001, 202, 3248.

19. Zhengtian, Y.; Marques, M.; Rausch, M. D.; Chien, J. C. W. J Polym Sci Part A: Polym Phys 1995, 33, 979.

20. Zohuri, G. H.; Jamjah, R.; Ahmadjo, S. Iran Polym J 2005, 14, 111.

21. Jamjah, R.; Zohuri, G. H.; Masnadi, M.; Ahmadjo, S.; Nekoomanesh, M. J Apply Polym Sci 2006, 101, 2216.

22. Mahdavi, H.; Badiei, A.; Zohuri, G. H.; Rezaee, A.; Jamjah, R.; Ahmadjo, S. J Apply Polym Sci 2007, 103, 1517.

23. Mortazavi, M. M.; Arabi, H.; Zohuri, G. H.; Ahmadjo, S.; Nekoomanesh, M.; Ahmadi, M. Macromol React Eng 2009, 3, 263. 
24. Mortazavi, M. M.; Arabi, H.; Zohuri, G. H.; Nekoomanesh, M.; Ahmadjo, S. International Conference on the Reaction Engineering of Polyolefins, Montreal, Canada 2008, p 85.

25. Wester, T. S.; Johnsen, H.; Kittilsen, P.; Rytter, E. Macromol Chem Phys 1998, 199, 1989.

26. Awudza, J. A. M.; Tait, P. J. T. J Polym Sci Polym Chem Ed 2008, 46, 267.

27. Ahmadi, M.; Jamjah, R.; Nekoomanesh, M.; Zohuri, G. H.; Arabi, H. Iran Polym J 2007, 16, 133.

28. Pipatpratanporn, P.; Jongsomjit, B.; Praserthdam, P. Iran Polym J 2007, 16, 123.

29. Dos Santos, J. H. S.; Da Rosa, M. B.; Cristiano, K.; Stedile, F. C.; Haag, M. C.; Dupont, J.; Forte, M. D. C. J Polym Sci Part A: Polym Chem 1999, 37, 1987.
30. Chao, C.; Pratchayawutthirat, W.; Praserthdam, P.; Shiono, T.; Rempel, G. L. Macromol Rapid Commun 2002, 23, 672.

31. Ver Strate, G. In Encyclopedia of Polymer Science and Engineering, 2nd ed.; Wiley Interscience, New York, 1986; Vol. 6, p 531, 541, 552.

32. Turek, D. E.; Landes, B. G.; Winter, J. M.; Sehanobish, K.; Chum, S. SPE ANTEC Tech Papers 1995, 2, 2270.

33. Starck, P. Eur Polym J 1997, 33, 339.

34. Lehtinen, C.; Starck, P.; Lofgren, B. J Polym Sci Part A: Polym Sci 1997, 35, 307.

35. Woo, L.; Westphal, S. P.; Ling, M. T. Polym Eng Sci 1994, 34, 420 .

36. Nielsen, L. E. Polymer Rheology; Marcel Dekker: New York, 1977. 